\title{
Comparing the effects of ketorolac and Paracetamol on postoperative pain relief after coronary artery bypass graft surgery. A randomized clinical trial
}

\author{
Fatemeh Javaherforooshzadeh ${ }^{1 *}$, Hasan Abdalbeygi ${ }^{2}$, Farahzad Janatmakan ${ }^{2}$ and Behnam Gholizadeh ${ }^{3}$
}

\begin{abstract}
Introduction: Pain management after coronary artery bypass graft (CABG) surgery remains challenging.

Objective: This study aimed to compare the effects of Ketorolac and Paracetamol on postoperative CABG pain relief.

Method: This double-blind randomized clinical trial study was conducted in Ahvaz, Iran, from September 2018December 2019. Two consecutive groups of 60 patients undergoing elective on-pump coronary artery bypass graft surgery.

Intervention: The patients were divided into $0.5 \mathrm{mg} / \mathrm{kg}$ of ketorolac $\mathrm{mg} / \mathrm{dl}$ and $10 \mathrm{mg} / \mathrm{kg}$ of Paracetamol after surgery for pain management. Primary outcomes were: visual analog pain scale (VAS) at the time point immediately after extubation (baseline) and at 6, 12, 24 and $48 \mathrm{~h}$ and the total dose of morphine consumption. Secondary outcomes included the hemodynamic variables, weaning time, chest tube derange, in-hospital mortality and myocardial infarction.

Statistical analysis: The data were analyzed using SPSS version 22(SPSS, Chicago, IL). The Mann-Whitney U-test was used to compare demographic data, VAS scores, vital signs, and side effects. Repeated measurements were tested within groups using Friedman's ANOVA and the Wilcoxon rank-sum test. Values were expressed as means \pm standard deviations. Statistical significance was defined as a $p$-value $<0.05$.
\end{abstract}

Results: Compared with baseline scores, there were significant declines in VAS scores in both groups throughout the time sequence $(P<0.05)$. The statistical VAS score was slightly higher in the Paracetamol group at most time points, except for the time of $6 \mathrm{~h}$. However, at 24 and $48 \mathrm{~h}$, the VAS score in group Paracetamol was significantly higher than in group Ketorolac. There were no significant differences between groups about hemodynamic variables.

Conclusion: The efficacy of ketorolac is comparable to that of Paracetamol in postoperative CABG pain relief. Trial registry: IRCT20150216021098N5. Registered at 2019-09-12.

Keywords: Ketorolac, Paracetamol, Postoperative analgesia, Visual analog score, Cardiac surgery

\footnotetext{
*Correspondence: f_javaherforoosh@yahoo.com

'Department of Cardiac Anesthesia, Ahvaz Anesthesiology and Pain Research Center, Ahvaz Jundishapur University of Medical Sciences, Ahvaz, Iran

Full list of author information is available at the end of the article
}

C C The Author(s). 2020 Open Access This article is licensed under a Creative Commons Attribution 4.0 International License, which permits use, sharing, adaptation, distribution and reproduction in any medium or format, as long as you give appropriate credit to the original author(s) and the source, provide a link to the Creative Commons licence, and indicate if changes were made. The images or other third party material in this article are included in the article's Creative Commons licence, unless indicated otherwise in a credit line to the material. If material is not included in the article's Creative Commons licence and your intended use is not permitted by statutory regulation or exceeds the permitted use, you will need to obtain permission directly from the copyright holder. To view a copy of this licence, visit http://creativecommons.org/licenses/by/4.0/. The Creative Commons Public Domain Dedication waiver (http://creativecommons.org/publicdomain/zero/1.0/) applies to the data made available in this article, unless otherwise stated in a credit line to the data. 


\section{Introduction}

Control of pain management after coronary artery bypass graft (CABG) surgery remains challenging. Incompetently controlled postoperative pain can increase catecholamine levels, triggering myocardial ischemia, stroke, and bleeding complications. Limiting patient mobility, poorly managed postoperative pain can increase the risk of deep vein thrombosis and pneumonia, in addition to harmful psychological consequences such as insomnia and demoralization $[1,2]$. Postoperative analgesia after cardiac surgery most commonly involves the use of intravenous and oral opioids. Intravenous (IV) opioids, such as morphine, are the analgesics commonly used to provide postoperative pain relief after CABG surgery [3, 4]. However, adverse effects, such as drowsiness, respiratory depression, excessive sedation, biliary spasm, depression of gastrointestinal motility, nausea and vomiting, and, particularly in the elderly, confusion caused by opioids may delay patient recovery and rehabilitation [3,5]. To limit these adverse effects without sacrificing adequate pain management, nonsteroidal anti-inflammatory drugs (NSAIDs), increasingly are being applied in the postoperative setting. Although NSAIDs have potential side effects (bleeding, gastrointestinal ulceration, renal dysfunction, and postoperative bone healing), several studies have noted low complication rates associated with their short-term use after CABG when administered to appropriately selected patients [6, 7].

Paracetamol is usually considered to be a frail inhibitor of the synthesis of prostaglandins (PGs). However, the in vivo effects of Paracetamol are alike to those of the discerning cyclooxygenase-2 (COX-2) inhibitors. It is the most commonly suggested pain-relieving for the treatment of acute pain [8]. Its benefit over NSAIDs is its lack of interfering with platelet functions. Moreover, it is safe to administer to patients with a history of peptic ulcers or asthma [9]. Its mechanism of action may involve a central inhibition of COX-2 [10, 11], inhibition of nitric oxide generation via a blockade of the $\mathrm{N}$-methylD-aspartate (NMDA) receptor, and activation of the descending serotonergic pathway. Paracetamol can cross the blood-brain barrier, producing a central analgesic effect $[12,13]$.

Ketorolac has been used for postoperative analgesia in combination with opioids. Several studies have reported that ketorolac is as effective as morphine or meperidine for analgesia after some types of surgical procedures [14]. However, because many studies report significant side effects of ketorolac, including coagulopathy, gastrointestinal problems, and nephrotoxicity there is increasing interest in the use of other classes of non-opioid analgesics $[15,16]$. It remains unknown whether NSAID utilization rates after CABG have changed since the boxed warning was issued, although some groups have reported their continued use to select cardiac surgery patients $[17,18]$. Management of postoperative pain is a major concern for anesthetists in patients undergoing CABG surgery. Due to the fact that the purpose of studies is to find the methods of pain management with the highest efficiency and the least side effects, and also according to the characteristics mentioned for Ketorolac and Paracetamol, the aim of our study was to compare the analgesic effects of Ketorolac and Paracetamol to find the appropriate anesthetic agent for postoperative CABG pain. Therefore, this study aimed to compare the effects of Ketorolac and Paracetamol on postoperative CABG pain relief.

\section{Material and method Study design}

This double-blind randomized clinical trial study was conducted in Golestan Hospital, Ahvaz, Iran, from September 2018-December 2019 with Ethics code: IR.AJUMS.REC.1398.050 from Anesthesiology and Pain Research Center, Ahvaz Jundishapur University of Medical Sciences, Ahvaz, Iran, and Trial registration number: IRCT20150216021098N5.

Sixty patients undergoing elective on-pump coronary artery bypass graft surgery. After clearly explaining the objective and potential risks and benefits of the study, a written consent form for participation in the study was obtained from all patients.

\section{Setting and patients: inclusion criteria}

Aged 30-70 years, ASA III, Both of sex, Ejection Fraction $\geq 30 \%$, undergoing elective CABG.

\section{Exclusion criteria included}

Severe hepatic and renal disease, consumption of antiinflammatory drugs or antipyretic drugs before the study, redo surgery, history of cerebrovascular accident (CVA), and thrombocytopenia.

Randomization: randomization was performed using computer-generated random digits to ensure that patients and investigators were blind to the treatment assignment before study entry, and the allocation was done 1:1 to receive either ketorolac or Paracetamol. Randomization was not performed until electronically confirming the eligibility criteria in the web-based case report form. Randomization was performed centrally without stratification. The sequence was generated by an independent statistician using a random number generator with a 1:1 allocation using random block sizes of 2 . In this study patients and researchers were blinded. 


\section{Sample size}

The sample size of this study was calculated using the sample size estimation formula. The 95\% confidence interval (CI) level was considered. The study population consisted of 90 patients. Based on the previous data [19]. After initial screening, 85 patients agreed to participate and provided informed consent. Among them, 25 patients did not have inclusion criteria (Five patients had $\mathrm{EF}<30 \%$, Ten patients had complex surgery, the surgical procedure of Five patients turned into off-pump, Five patients were given antipsychotic drugs or history of seizure). Finally, 60 patients were enrolled in the study and were assigned into two groups of Paracetamol and ketorolac, 30 patients each (Fig. 1).

\section{Anesthesia protocol}

After arrival to the operation room, standard monitoring included five-lead electrocardiography, pulse oximetry and arterial line for continuous blood pressure monitoring and blood gases were inserted. A standard anesthesia technique was used for all patients. The anesthetic drug doses were calculated according to body weight; midazolam at $0.1 \mathrm{mg} / \mathrm{kg}$ was given as IV premedication. Induction of anesthesia was induced fentanyl $15 \mu \mathrm{g} / \mathrm{kg}$, propofol $1 \mathrm{mg} / \mathrm{kg}$, and pancuronium $0.1-0.15 \mathrm{mg} / \mathrm{kg}$ ). Anesthesia was maintained with a continues infusion of propofol $1-1.5 \mathrm{mg} / \mathrm{kg} / \mathrm{h}$, fentanyl $4 \mu \mathrm{g} / \mathrm{kg} / \mathrm{h}, 0.25 \mathrm{mg} / \mathrm{kg} /$ h midazolam, and $0.3 \mathrm{mg} / \mathrm{kg} / \mathrm{h}$ cisatracurium until the end of surgery. Isoflurane supplementation was used at the discretion of the attending anesthesiologist. After induction of general anesthesia, a central venous catheter was introduced. For initiation of cardiopulmonary bypass, $350 \mathrm{u} / \mathrm{kg}$ heparin was injected to all patients. Heparin dosage was attuned based on goal ACT 450-480 s. After the bypass was terminated, protamine $1 \mathrm{mg} / \mathrm{kg}$ was given for the reversal of heparin. Cardiac surgery and postoperative management were standardized.

After surgery, all the patients were admitted to the cardiovascular ICU, with a standard protocol for sedation, analgesia (propofol $0.5 \mathrm{mg} / \mathrm{kg} / \mathrm{h}$ and morphine sulfate $0.1 \mathrm{mg} / \mathrm{kg} / \mathrm{h}$ ), and management of mechanical ventilation (SIMV mode of ventilation).

\section{Intervention}

Immediately after the transfer of patients to ICU, the intervention began. The patients in the ketorolac group were administered at a rate of $0.5 \mathrm{mg} / \mathrm{kg}$ IV admixed with $100 \mathrm{ml}$ of normal saline each $6 \mathrm{~h}$ for $24 \mathrm{~h}$. A bolus may be given at the start of therapy if desired. The patients in the Paracetamol group were given $10 \mathrm{mg} / \mathrm{kg}$ IV of Paracetamol (mixed with normal saline to a total volume of $100 \mathrm{ml}$ ) for $30 \mathrm{~min}$ each $6 \mathrm{~h}$ for $24 \mathrm{~h}$. (Dose of ketorolac determined based on Howard et.al study [20].

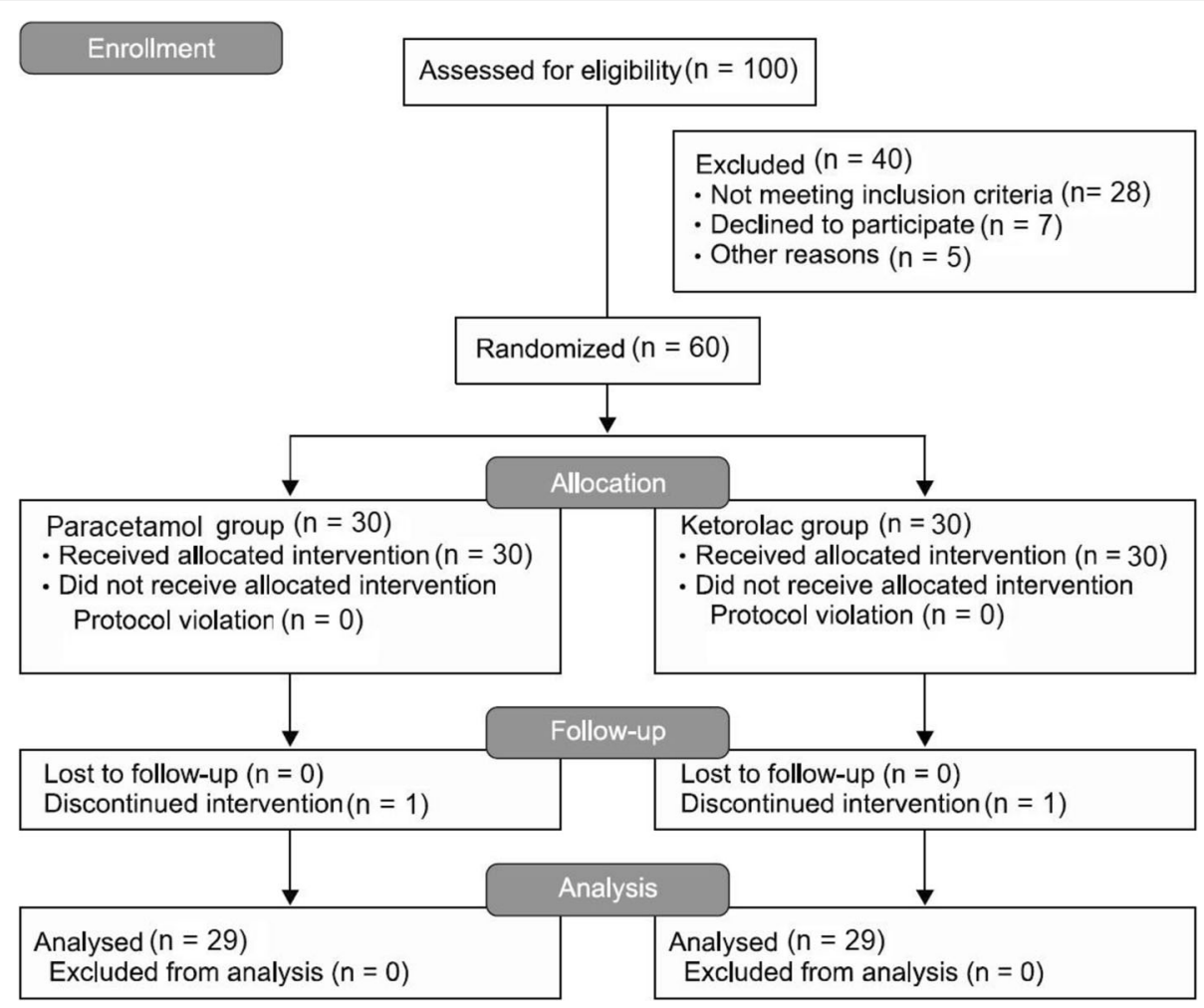

Fig. 1 The consort flow chart 
Patients were extubated according to the following criteria: responsive and cooperative, $\mathrm{pO} 2$ of 80-100, oxygenation index of $\mathrm{pO} 2 / \mathrm{FiO} 2>300$, and hemodynamic stability without any inotropes.

After extubation, the patients had access to morphine sulfate with a patient-controlled analgesia device (PCA device; Graseby 3300P, Hoyer, Bremen, Germany) using a standardized protocol: bolus dose of $2 \mathrm{mg}$, dose duration of $2 \mathrm{~min}$, lockout interval of $13 \mathrm{~min}$ ( $15 \mathrm{~min}$ effective lockout time), and with no background infusion and no upper dose limit. Before commencing the PCA, the nurses in the PACU were allowed to give morphine sulfate $2 \mathrm{mgIV}$ before extubation for the treatment of pain if required. Morphine consumption was recorded from the PCA device at the end of the 48 -h study period. Per protocol, the primary efficacy variable was cumulative morphine consumption (the combined amount administered via the PCA device and given as rescue doses) at the end of the 48-h postoperative period. If pain relief was insufficient (VAS score $>3$ at rest), nurses were allowed to give an extra bolus of morphine $2 \mathrm{mg}$ IV as a rescue analgesic once an hour. Renal function test (serum creatinine) were measured the evening before surgery and $72 \mathrm{~h}$ after surgery. Bleeding after surgery was measured as chest tube drainage. The number of red cell units transfused was recorded.

Primary outcomes were: visual analog pain scale (VAS) at the time point immediately after extubation (baseline) and at $6,12,24$ and $48 \mathrm{~h}$ and the total dose of morphine consumption. Secondary outcomes included the hemodynamic variables, weaning time, postoperative bleeding, myocardial infarction, CVA, TIA, in-hospital mortality and postoperative serum creatinine.

\section{VAS score assessment}

Pain intensity levels were subjectively measured using a $10 \mathrm{~cm}$ visual analog pain scale (VAS, $0=$ no pain to $10=$ unbearable pain). We assessed VAS and hemodynamic variables (systolic blood pressure, diastolic blood pressure, heart rate and other parameters) of each regimen immediately after extubation (baseline) and at 6, 12, 24, and $48 \mathrm{~h}$.

\section{Statistical analysis}

Numerical variables were reported as mean \pm standard deviation (SD). Quantitative and qualitative variables were measured by independent $\mathrm{t}$-test, and ANOVA test respectively. $P$ value $\leq 0.05$ was considered to be statistically significant. All analyses were performed using SPSS for Windows version 22.0 (SPSS Inc., Chicago, IL, USA).

\section{Results}

During the study period from September 2018-December 2019, 100 patients undergoing elective on-pump
CABG surgery were eligible to participate in the trial. Forty patients did not have inclusion criteria Finally, 60 patients were enrolled in the study and were assigned into two groups of ketorolac and Paracetamol, 30 patients each. (Fig. 1).

There were no significant differences between the two groups in terms of demographic characteristics including age, male/female ratio, antiplatelet using, Euro Score \| and duration of cross-clamp time $(P>0.05)$ (Table 1$)$.

There were significant differences about morphine consumption in two groups at $24 \mathrm{~h}(0.29 \pm 0.41 \mathrm{mg}$ in Paracetamol group versus $1.71 \pm 0.53 \mathrm{mg}$ in ketorolac group $p=0.027)$ and $48 \mathrm{~h}(0.22 \pm 0.15 \mathrm{mg}$ in Paracetamol versus $2.18 \pm 0.52 \mathrm{mg}$ in ketorolac group $p=0.007$ ) after extubation (Fig. 2).

Compared with baseline scores, there were significant declines in VAS scores in both groups throughout the time sequence The statistical VAS score was higher in the Paracetamol group at most time points, except for the time of $6 \mathrm{~h}$. However, at 24 and $48 \mathrm{~h}$, the VAS score in group Paracetamol was significantly higher than in group Ketorolac $(\mathrm{P}<0.05)$ (Fig. 3).

Comparison of the two groups receiving ketorolac and Paracetamol showed that there was no significant difference between the two groups in terms of platelet count, bleeding time, and chest tube derange Table 2 . Hemodynamic parameters and $\mathrm{SPO} 2$ and postoperative bleeding at different times were not different between the two groups. Table 3.

Weaning time significantly lower in the Paracetamol group than the ketorolac group $(p=0.003)$. (Table 4$)$.

Comparison of the two groups receiving ketorolac and Paracetamol showed that there was no significant difference between the two groups in terms of the hospital mortality rate MI, CVA, TIA, and postoperative serum creatinine $(P>0.05)$ Table 4 . There were no differences between-group in renal function tests.

\section{Discussion}

Control of pain management in the postoperative care setting is of the greatest importance for patients who experienced CABG. Therefore, pharmacological and interventional approaches have been developed for postoperative analgesia. Currently, there is an increase in the mean age of the patients and the number of comorbidities in patients undergoing CABG. Overall, a method of postoperative analgesia that is cost-effective and comfortable for the patient with minimum complication rates and side effects which also shortens the duration of postoperative stay should be chosen. However, postoperative pain managing is often incomplete by the side effects of opioids; especially when used alone in large doses for an extended period, opioids can lead to acute tolerance and, more seriously, respiratory depression 
Table 1 Demographic Data of patients in Paracetamol and ketorolac groups

\begin{tabular}{llll}
\hline Parameter & Paracetamol $(\boldsymbol{n}=30)$ & Ketorolac group $(\boldsymbol{n}=30)$ & $\boldsymbol{P}$-value \\
\hline Male, $\mathrm{n}(\%)$ & $18(60)$ & $19(63.33)$ & 0.453 \\
Age (year) & $58.41 \pm 1.82$ & $61.83 \pm 1.54$ & 0.159 \\
Weight (kg) & $70.63 \pm 10.10$ & $74.80 \pm 31.14$ & 0.475 \\
Height (cm) & $173.03 \pm 10.16$ & $163.29 \pm 27.20$ & 0.063 \\
Outpatient use of NSAIDs or antiplatelet, n (\%) & $20(67)$ & $21(70)$ & 0.21 \\
Euro Score II (\%), mean \pm SD & $2.63 \pm 2.65$ & $2.86 \pm 2.83$ & 0.489 \\
Duration of AO (min) & $55 \pm 38$ & $49 \pm 30$ & 0.09 \\
\hline
\end{tabular}

Values are mean \pm sd or number of patients.; Euro Score $\|:$ _ European System for Cardiac Operative Risk Evaluation; AO Aortic occlusion.SD Standard deviation

and hypotension. For these explanations, multimodal methods that add non-opioid agents to opioid-based regimens are promising. This study aimed to compare the effects of Ketorolac and Paracetamol on postoperative pain management. The main finding in the present study was that ketorolac more effective than Paracetamol to manage postoperative pain patients undergoing CABG surgery. Also, it can reduce postoperative additional analgesic requirements in comparison to Paracetamol with no additional adverse effects. This finding was similar to Amini S et al. study (20). Of course, their study was in congenital cardiac patients.

NSAIDs block the synthesis of prostaglandins through the inhibition of COX-1 and COX-2, thus lowering the production of acute inflammatory response mediators. By decreasing the inflammatory response to surgical trauma, NSAIDs reduce peripheral nociception. NSAIDs also appear to have a central analgesic mechanism, possibly through the inhibition of prostaglandin synthesis within the spinal cord. In general, NSAIDs have a low side-effect profile when administered for the shortterm purpose of perioperative analgesia after cardiac surgery $[21,22]$.

Ketorolac is effective at reducing pain, and several studies have reported its safety and efficacy in the perioperative period. In many reports, the use of ketorolac as an adjuvant to a PCA opioid resulted in an opioidsparing effect ranging from 16 to 33\% [23]. The hypothesis by which ketorolac exerts these possible beneficial effects is proposed to be related to its COX-1 selectivity and minimal inhibition of COX-2 [24]. As previously discussed, the boxed warning for NSAIDs arose from specific data for the COX-2 selective NSAID, celecoxib [25] COX-2 inhibitors selectively reduce prostacyclin synthesis with no effect on thromboxane A2. Prostacyclin is a potent inhibitor of platelet aggregation; its

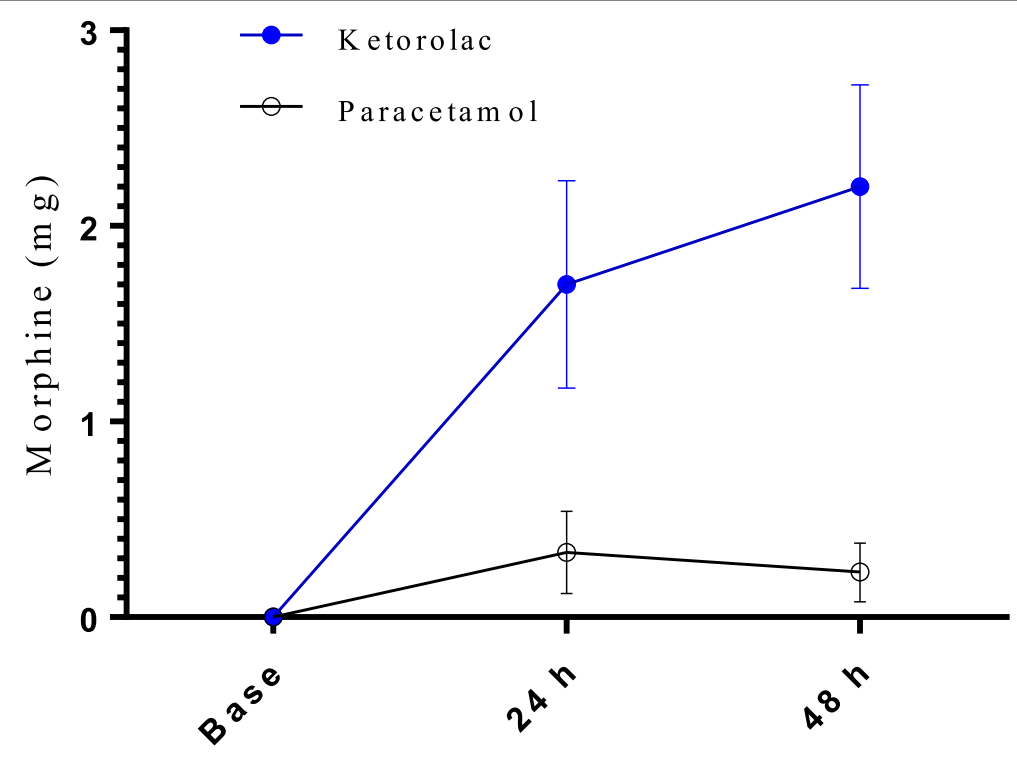

T im e

Fig. 2 VAS score after the operation. There were significant VAS score declines in both groups $(P<0.05)$ 


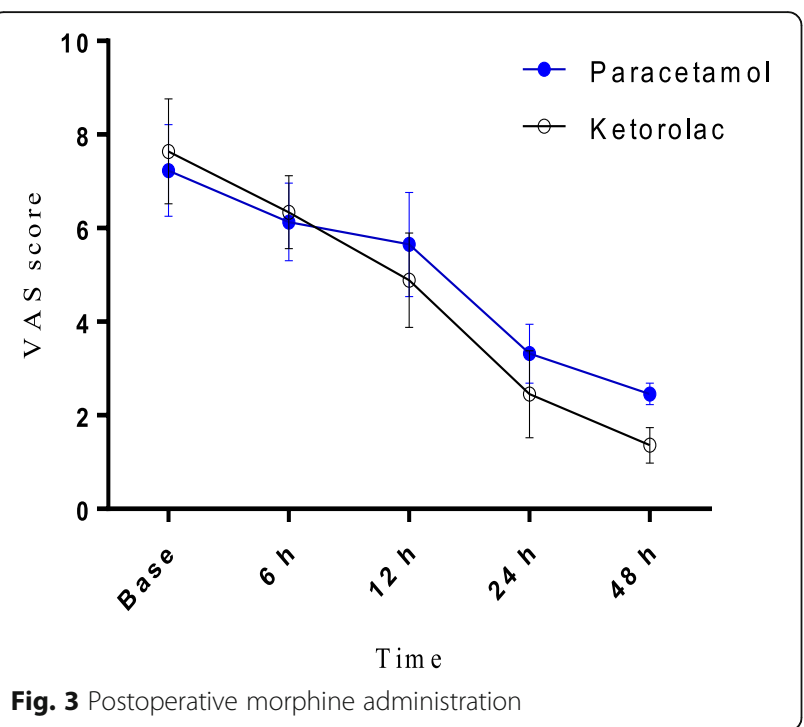

selective blockade by COX-2 inhibitors may upset thrombosis homeostasis and cause adverse cardiovascular events. Ketorolac, on the other hand, potently blocks platelet aggregation through thromboxane A2 inhibition $[24,26]$. This may be beneficial in patients with aspirin resistance to prevent CABG graft failure. The period of this antiplatelet effect can be last up to $24 \mathrm{~h}$ after a distinct dose. Additionally, the antiplatelet effects of ketorolac may offset the risk of hemorrhage in postoperative patients who may be hypercoagulable following exactly off-pump CABG surgery [17].

The authors previously reported the results of a randomized trial that found that oral naproxen is effective as an adjunct for the optimization of pain control and lung recovery after CABG, without increasing the risk of postoperative complications. In contrast to naproxen, intravenous ketorolac can be provided earlier in the postoperative period before the resumption of oral intake. Ketorolac provides an analgesic effect similar to that of fentanyl, but with a lower incidence of postoperative nausea and somnolence, and leads to an earlier return of bowel function. (15) With these advantages over opioids, ketorolac administration ultimately may shorten hospital length of stay.
Table 3 Effect of administration of ketorolac and Paracetamol on hemodynamic variables

\begin{tabular}{llll}
\hline parameter & Paracetamol $(\boldsymbol{n}=30)$ & Ketorolac $(\boldsymbol{n}=30)$ & $\boldsymbol{P}$-value \\
\hline MAP & $87.742(11.026)$ & $86.451(8.958)$ & 0.59 \\
HR & $86.2 \pm 7.2$ & $85.5 \pm 11.7$ & 0.44 \\
SpO2 & $98.4 \pm 1.4$ & $98.4 \pm 1.3$ & 0.8
\end{tabular}

HR Heart rate; MAP Mean arterial blood pressure; SpO2 Arterial oxygen saturation

Paracetamol has been studied in many surgical settings such as functional endoscopic sinus surgery, cholecystectomy, hysterectomy, and orthopedic surgeries with variable favorable results $[27,28]$. The direction of acetaminophen via a nasogastric tube or rectally after surgery is insufficient to accomplish an antipyretic plasma concentration $(10 \mathrm{mg} / \mathrm{ml})$; this was probably mainly because of late gastric emptying after anesthesia and surgery $[13,29]$ In a study conducted by Cattabriga et al., they found that, in patients undertaking cardiac surgery, intravenous paracetamol in combination with tramadol delivers effective pain control [30, 31].

Paracetamol has resulted in hypotension in critically ill patients although this effect could be explained as an allergic phenomenon [32]. The remaining prostaglandin inhibitors seem to exert less marked cardiac depressant effect; in fact, the hemodynamic safety of other NSAIDs such as diclofenac and ketorolac used at antipyretic doses and analgesic doses has been reported in several studies [30].

The hemodynamic effects of NSAIDs used for postoperative pain control in patients undergoing major vascular surgery have been reported in a few studies [33, 34]. Although exogenous administration of prostaglandins has marked hemodynamic repercussions, exogenous inhibition of prostaglandin synthesis has a little hemodynamic effect. This could reflect a balance between the reduction in synthesis of prostaglandins with vasodilator and vasoconstrictor actions, with a neutral overall effect. However, NSAIDs must be used cautiously in clinical situations in which prostaglandins have been shown to have advantageous therapeutic effects, such as circulatory insufficiency, shock, myocardial ischemia, coronary spasm, and systemic and pulmonary

Table 2 Effect of administration of ketorolac and Paracetamol on Bleeding Time, Platelet and post-operative bleeding

\begin{tabular}{llll}
\hline parameter & Paracetamol $(\boldsymbol{n}=30)$ & $\begin{array}{l}\text { Ketorolac } \\
(\boldsymbol{n}=30)\end{array}$ & $\boldsymbol{p}$-value \\
\hline BT in 24 h. (S) & $121.1 \pm 2.73$ & $126.8 \pm 3.41$ & 0.417 \\
BT in 48 h. (S) & $129.6 \pm 34.56$ & $132.4 \pm 23.87$ & 0.356 \\
Decrease in platelet, median & $74(11-121)$ & $72(19-153)$ & 0.17 \\
Post-operative bleeding (CC) & $285.25 \pm 65.6$ & $302.05 \pm 68.76$ & 0.65 \\
\hline
\end{tabular}

BT Bleeding Time; S Second; CC Milliliter 
Table 4 Effect of administration of ketorolac and Paracetamol on outcomes

\begin{tabular}{llll}
\hline Parameter & Paracetamol $(\boldsymbol{n}=30)$ & Ketorolac $(\boldsymbol{n}=30)$ & $\boldsymbol{P}$-value \\
\hline WT, (hr.) & $11.76 \pm 1.21$ & $18.56 \pm 1.14$ & $0.003^{\mathrm{a}}$ \\
MI, n (\%) & $0(0)$ & $0(0)$ & - \\
Hospital mortality, n (\%) & $0(0)$ & $0(0)$ & - \\
CVA, n(\%) & $0(0)$ & $0(0)$ & - \\
TIA, n(\%) & $0(0)$ & $0(0)$ & - \\
Postoperative Cr (mg/dl) & $0.99 \pm 0.12$ & $1.01 \pm 0.16$ & 0.81 \\
\hline
\end{tabular}

hr Hour; $n$ Number; WT Weaning time;MI Myocardial infarction; CVA Cerebral vascular accident TIA Transient ischemic attack SD Standard deviation; Cr Serumcreatinine; a means significant

hypertension; also, NSAIDs may antagonize the effect of antihypertensive medication. In the present study, such patients were excluded and therefore no evaluation of hemodynamic stability when the drugs were present was made.

Our study found no association between the use of $0.5 \mathrm{mg} / \mathrm{kg}$ ketorolac and mortality, MI, or clinically important hemorrhage. These results, however, are limited by unexpected differences in the baseline characteristics of the number of on-pump CABG patients and STS risk scores. On-pump CABG means a patient placed on cardiopulmonary bypass throughout surgery [35]. The STS risk score is intended for all patients who undergo CABG surgery and helps as a prognosticator of postoperative mortality [36].

\section{Limitations}

This study has several limitations. First; the sample size was small second; this study was single-centered. We recommended future trials with a large sample size, multi-center and long duration of follow-up.

\section{Conclusion}

In conclusion, ketorolac and Paracetamol may be produced marked postoperative pain relief after cardiac surgery. The analgesic effects of these compounds were not associated with a clinically significant impairment in hemodynamic function and mortality, MI, or clinically significant bleeding in postoperative CABG patients. So further study with similarly coordinated groups and the larger sample size is necessary to sufficiently determine the cardiovascular risks associated with administration of IV ketorolac.

\footnotetext{
Abbreviations

CABG: Coronary artery bypass graft; VAS: Visual analog pain scale; COX2: Cyclooxygenase-2 inhibitors; NMDA : N-methyl-D-aspartate; Euro Score II : European system for cardiac operative risk evaluation; AO : Aortic occlusion; MI: Myocardial infarction; CVA: Cerebral vascular accident; TIA: Transient ischemic attack
}

\section{Acknowledgments}

This paper was a part of a thesis with Ethics code IR.AJUMS.REC.1398.050. This study was designed as a placebo-controlled double-blind clinical trial
(IRCT20150216021098N5). We sincerely thank the patients who cooperated with us in this project and supported the research team.

\section{Authors' contributions}

Fatemeh Javaherforooshzadeh and Hasan Abdalbeygi collected data and drafted the manuscript. Behnam Gholizadeh provided study materials and patients' information. Farahzad Janatmakan conceived of the study and participated in its design. All authors read and approved the final manuscript.

\section{Funding}

Ahvaz Jundishapur University of Medical Sciences.

\section{Availability of data and materials}

All data were retrieved from the institutional database and are available from the corresponding author upon reasonable request.

\section{Ethics approval and consent to participate}

"The local Ethics Committee of Ahvaz Jundishapur University of Medical Sciences, Ahvaz, Iran, approved all of the procedures of this study. IR.AJUMS.REC.1398.050, and Trial registration number: IRCT20150216021098N5.

Written informed consent was collected from the patients.

\section{Consent for publication}

Authors provide formal written Consent to Publish before publication.

\section{Competing interests}

The authors report no conflict of interest.

\section{Author details}

${ }^{1}$ Department of Cardiac Anesthesia, Ahvaz Anesthesiology and Pain Research Center, Ahvaz Jundishapur University of Medical Sciences, Ahvaz, Iran.

${ }^{2}$ Department of Anesthesia, Ahvaz Anesthesiology and Pain Research Center, Ahvaz Jundishapur University of Medical Sciences, Ahvaz, Iran.

${ }^{3}$ Atherosclerosis Research Center, Ahvaz Jundishapur University of Medical Sciences, Ahvaz, Iran.

Received: 5 February 2020 Accepted: 28 April 2020

Published online: 11 May 2020

\section{References}

1. Apfelbaum JL, Chen C, Mehta SS, Gan TJ. Postoperative pain experience: results from a national survey suggest postoperative pain continues to be undermanaged. Anesth Analg. 2003;97(2):534-40.

2. Brennan F, Carr DB, Cousins M. Pain management: a fundamental human right. Anesth Analg. 2007;105(1):205-21.

3. Liu SS, Block BM, Wu CL. Effects of perioperative central neuraxial analgesia on outcome after coronary artery bypass surgery - a meta-analysis. Anesthesiology. 2004;101(1):153-61.

4. Bainbridge D, Martin JE, Cheng DC. Patient-controlledversus nursecontrolled analgesia after cardiac surgery - a meta-analysis. Can J Anesth. 2006;53(5):492.

5. Ucak A, Onan B, Sen H, Selcuk I, Turan A, Yilmaz ATJJ. Anesthesia v: The effects of gabapentin on acute and chronic postoperative pain after 
coronary artery bypass graft surgery. J Cardiothorac Vasc Anesth. 2011;25(5): 824-9.

6. Hynninen MS, Cheng DC, Hossain I, Carroll J, Aumbhagavan SS, Yue R, Karski JM. Non-steroidal anti-inflammatory drugs in treatment of postoperative pain after cardiac surgery. Can J Anesth. 2000;47(12):1182-7.

7. Kulik A, Ruel M, Bourke M, Sawyer L, Penning J, Nathan H, Mesana T, Bédard P. Postoperativenaproxen after coronary artery bypass surgery: a doubleblind randomizedcontrolledtrial. Eur J Cardiothorac Surg. 2004;26(4):694700

8. Sachs CJ. Oral analgesics for acute nonspecific pain. Am Fam Physician. 2005;71(5):913-8.

9. Hyllested $\mathrm{M}$, Jones $\mathrm{S}$, Pedersen $\mathrm{JL}$, Kehlet $\mathrm{H}$. Comparative effect of paracetamol, NSAIDs or their combination in postoperative pain management: a qualitative review. Br J Anaesth. 2002;88(2):199-214.

10. Graham GG, Scott KF. Mechanism of action of paracetamol. Am J Ther 2005;12(1):46-55.

11. Remy C, Marret E, Bonnet F. Effects of acetaminophen on morphine sideeffects and consumption after major surgery: meta-analysis of randomized controlled trials. Br J Anaesth. 2005;94(4):505-13.

12. Bonnefont J, Courade JP, Alloui A, Eschalier A. Antinociceptive mechanism of action of paracetamol. Drugs. 2003:63:1-4.

13. Bannwarth B, Netter P, Lapicque F, Gillet P, Pere P, Boccard E, Royer RJ, Gaucher A. Plasma and cerebrospinal fluid concentrations of paracetamol after a single intravenous dose of propacetamol. Br I Clin Pharmacol. 1992; 34(1):79-81.

14. De Oliveira GS, Agarwal D, Benzon HT. Perioperative single dose ketorolac to prevent postoperative pain: a meta-analysis of randomized trials. Anesth Analg. 2012;114(2):424-33.

15. Brown J, Crawford TJ, Allen C, Hopewell S, Prentice A. Nonsteroidal antiinflammatory drugs for pain in women with endometriosis. Cochrane Database Syst Rev. 2017;1 (1):CD004753. https://doi.org/10.1002/14651858. CD004753.pub4 PMID: 28114727; PMCID: PMC6464974.

16. Tabrizian P, Giacca M, Prigoff J, Tran B, Holzner ML, Chin E, Palese M, Herron D, Arvelakis A, Rudow DL, Florman S. Renal safety of intravenous ketorolac use after donor nephrectomy. Prog Transplant. 2019;29(3):283-6.

17. Engoren M, Hadaway J, Schwann TA, Habib RH. Ketorolac improves graft patency after coronary artery bypass grafting: a propensity-matched analysis. Ann Thorac Surg. 2011:92(2):603-9.

18. Engoren MC, Habib RH, Zacharias A, Dooner J, Schwann TA, Riordan CJ, Durham SJ, Shah A. Postoperative analgesia with ketorolac is associated with decreased mortality after isolated coronary artery bypass graft surgery in patients already receiving aspirin: a propensity-matched study. J Cardiothorac Vasc Anesth. 2007;21(6):820-6.

19. Sakpal T. Sample size estimation in clinical trial. Perspect Clin Res. 2010;1(2): 67.

20. Howard ML, Warhurst RD, Sheehan C. Safety of continuous infusion ketorolac in postoperative coronary artery bypass graft surgery patients. Pharmacy. 2016;4(3):22

21. Rahman MM, Alam MB, Islam MA, Haque AA. Non steroidal anti inflammatory drugs-an overview. J Med. 2006;7(1):20-31.

22. Jahnavi K, Reddy PP, Vasudha B, Narender BJJDD. Therapeutics: nonsteroidal anti-inflammatory drugs: an overview. J Drug Deliv Ther. 2019;9(1s):442-8.

23. Ready LB, Brown CR, Stahlgren LH, Egan KJ, Ross B, Wild L, Moodie JE, Jones SF, Tommeraasen M, Trierwieler M. Evaluation of intravenous ketorolac administered by bolus or infusion for treatment of postoperative pain a double-blind, placebo-controlled, multicenter study. Anesthesiology. 1994; 80(6):1277-86

24. Warner TD, Giuliano F, Vojnovic I, Bukasa A, Mitchell JA, Vane JR. Nonsteroid drug selectivities for cyclo-oxygenase-1 rather than cyclo-oxygenase-2 are associated with human gastrointestinal toxicity: a full in vitro analysis. Proc Natl Acad Sci. 1999;96(13):7563-8.

25. Nussmeier NA, Whelton AA, Brown MT, Langford RM, Hoeft A, Parlow JL, Boyce SW, Verburg KM. Complications of the COX-2 inhibitors parecoxib and valdecoxib after cardiac surgery. N Engl J Med. 2005;352(11):1081-91.

26. Funk CD, FitzGerald GAJJ. COX-2 inhibitors and cardiovascular risk. J Cardiovasc Pharmacol. 2007;50(5):470-9.

27. Berger MM, Berger-Gryllaki M, Wiesel PH, Revelly J-P, Hurni M, Cayeux C, Tappy L, Chioléro RJC. Intestinal absorption in patients after cardiac surgery. Crit Care Med. 2000;28(7):2217-23.
28. Arslan M, Celep B, Çiçek R, Kalender HÜ, Yılmaz H. Comparing the efficacy of preemptive intravenous paracetamol on the reducing effect of opioid usage in cholecystectomy. J Res Med Sci. 2013;18(3):172.

29. Jebaraj B, Maitra S, Baidya DK, Khanna P. Intravenous paracetamol reduces postoperative opioid consumption after orthopedic surgery: a systematic review of clinical trials. Pain Res Treat. 2013;2013.

30. Douzjian DJ, Kulik A. Old drug, new route: a systematic review of intravenous acetaminophen after adult cardiac surgery. I Cardiothorac Vasc Anesth. 2017;31(2):694-701.

31. Cattabriga I, Pacini D, Lamazza G, Talarico F, Di Bartolomeo R, Grillone G, Bacchi-Reggiani L. Intravenous paracetamol as adjunctive treatment for postoperative pain after cardiac surgery: a double blind randomized controlled trial. Eur J Cardiothorac Surg. 2007;32(3):527-31.

32. Jóźwiak-Bebenista M, Nowak JZ. Paracetamol: mechanism of action, applications and safety concern. Acta Pol Pharm. 2014;71(1):11-23.

33. Maddali MM, Kurian E, Fahr J. Extubation time, hemodynamic stability, and postoperative pain control in patients undergoing coronary artery bypass surgery: An evaluation of fentanyl, remifentanil, and nonsteroidal antiinflammatory drugs with propofol for perioperative and postoperative management. J Clin Anesth. 2006;18(8):605-10.

34. Roediger L, Larbuisson R, Lamy M. New approaches and old controversies to postoperative pain control following cardiac surgery. Eur J Anaesthesiol. 2006;23(7):539-50

35. Møller $\mathrm{CH}$, Steinbrüchel DA. Off-pump versus on-pump coronary artery bypass grafting. Curr Cardiol Rep. 2014;16(3):455.

36. Bhatt DL, Drozda JP, Shahian DM, Chan PS, Fonarow GC, Heidenreich PA, Jacobs JP, Masoudi FA, Peterson ED, Welke KF. ACC/AHA/STS statement on the future of registries and the performance measurement enterprise: a report of the American College of Cardiology/American Heart Association Task Force on Performance Measures and The Society of Thoracic Surgeons. J Am Coll Cardiol. 2015;66(20):2230-45.

\section{Publisher's Note}

Springer Nature remains neutral with regard to jurisdictional claims in published maps and institutional affiliations.

Ready to submit your research? Choose BMC and benefit from:

- fast, convenient online submission

- thorough peer review by experienced researchers in your field

- rapid publication on acceptance

- support for research data, including large and complex data types

- gold Open Access which fosters wider collaboration and increased citations

- maximum visibility for your research: over $100 \mathrm{M}$ website views per year

At BMC, research is always in progress.

Learn more biomedcentral.com/submissions 